\title{
MODALIDADES DE EJERCICIO DE LA COMPETENCIA ESTATAL EN MATERIA DE SANIDAD EXTERIOR (PARTICIPACION EN LA MISMA DE LAS COMUNIDADES AUTONOMAS: SENTENCIA 252/88)
}

\author{
POR \\ ARMANDO SALVADOR SANCHO
}

\begin{abstract}
SUMARIO: I. INTRODUCCION; -II. LA CONSECUCION DEL "MERCADO UNICO": SUS EFECTOS EN LA DISTRIBUCION COMPETENCIAL; 2.1. Sentido de la evolución. 2.2. Sus consecuencias. 2.2.1. La modificación de los tradicionales instrumentos de la acción administrativa; 2.2.2. La "yuxtaposición" de las materias y el posible "vaciamiento" competencial. 2.3. Tesis que se propugna. 2.3.1. La necesidad de colaboración entre Administraciones; 2.3.2. Concurrencia de la materia "sanitaria" y del "comercio exterior": la determinación de la prevalencia. -III. LA SENTENCIA 252/88, DE 20 DE DICIEMBRE. -IV. CONCLUSIONES Y PROPUESTAS. 4.1. Conclusiones. 4.2. Propuestas.
\end{abstract}

MODALIDADES DE EJERCICIO DE LA COMPETENCIA ESTATAL EN MATERIA DE SANIDAD EXTERIOR

(PARTICIPACION EN LA MISMA DE LAS COMUNIDADES

AUTONOMAS: SENTENCIA 252/88, FUNDAMENTO JURIDICO 3%)

\section{INTRODUCCION}

Las competencias del Estado en materia de sanidad y comercio "exteriores", de un lado, y las de las Comunidades Autónomas en relación con la sanidad y comercio "interiores", ilustran con claridad sobre los problemas que se han de derivar cuando el "mercado úni$\mathrm{co}^{\prime \prime}$ sea una realidad en la Comunidad Europea.

La Constitución atribuye al Estado la competencia para dictar las bases y coordinación general de la sanidad (artículo 149.1.16ㄹ) y permite (artículo 148.1.21a) que las Comunidades Autonómicas ostenten competencias en materia de sanidad e higiene. En virtud de lo anterior, todas las Comunidades Autonómicas han asumido estatutariamente competencias de desarrollo legislativo y ejecución de las bases sanitarias establecidas por el Estado. En todo caso éste último tiene 
competencia exclusiva en materia de sanidad exterior (artículo 149.1.16 de la Constitución).

Estas previsiones del bloque de la Constitucionalidad han determinado que las Comunidades Autónomas asuman, en el marco de la normativa básica estatal, gran número de funciones normativas y ejecutivas, siendo expresión de esa asunción los Reales Decretos de traspasos en materia de "sanidad" (y en concordancia con ello los Reales Decretos de traspasos en materia de sanidad animal, materia ésta que se conecta también con la sanidad humana en la medida en que las enfermedades de los animales sean difusibles al hombre).

La Ley 14/1986, de 25 de abril, General de Sanidad refleja perfectamente lo ya indicado cuando, en su Título II, Capítulo II y IV, se refiere, respectivamente, a "las competencias del Estado" y a la "Alta inspección". De acuerdo con lo allí previsto al Estado le corresponde:

a) La "sanidad exterior" que incluye todas las actividades que "se realicen en materia de vigilancia y control de los posibles riesgos para la salud derivados de la importación, exportación o tránsito de mercancías y del tráfico internacional de viajeros" (artículo 38.2).

b) Toda una serie de funciones de naturaleza diversa que pueden ser consideradas como "bases de la sanidad" pero que han de ejercerse "sin menoscabo de las competencias de las Comunidades Autónomas" (artículo 40), con lo que parece reconocerse que, en algunos aspectos al menos de los allí relacionados, existiría concurrencia competencial entre el Estado y las Comunidades Autónomas.

c) La Alta Inspección, "como función de garantía y verificación del cumplimiento de las competencias estatales y de las Comunidades Autónomas en materia de sanidad" (artículo 43).

Teniendo en cuenta lo anterior, es claro que el bloque de la Constitucionalidad ha realizado una importante redistribución de las actuaciones administrativas en materia sanitaria, correspondiendo a las Comunidades Autónomas las funciones normativas de desarrollo y de ejecución en lo que a sanidad interior se refiere.

Se produce así una importante diferenciación entre la sanidad interior y la sanidad exterior, permaneciendo esta última atribuida a la Administración del Estado en exclusiva.

\section{LA CONSECUCION DEL "MERCADO UNICO": SUS EFECTOS EN LA DISTRIBUCION COMPETENCIAL}

\subsection{Sentido de la evolución}

Es ya considerable el número de Directivas que se han aprobado por las instituciones comunitarias para armonizar las legislacio- 
nes de los diferentes Estados miembros en materia sanitaria. De la lectura detallada de sus preámbulos se derivan una serie de notas que permiten apreciar las finalidades perseguidas:

a) Se trata de normas de "policía sanitaria", esto es, tratan de garantizar la salud humana mediante el establecimiento de medidas muy rigurosas de sanidad e higiene para diversos productos.

b) Contribuyen de forma decisiva a la constitución del "mercado único" pues, teniendo en cuenta la diversidad de las legislaciones nacionales,permiten superar el freno que para los intercambios entre Estados miembros supone la diversidad citada.

c) Las Directivas se van extendiendo a un número creciente de productos.

d) Si las primeras Directivas conllevaban la vigencia de una "doble" regulación en los Estados (la que afectaba a los productos destinados al intercambio con otros Estados miembros y la que regulaba los productos comercializables exclusivamente en el seno de cada Estado), la proximidad de 1992 determinaría la paulatina desaparición de esta dualidad normativa interna. Ello habría de culminar en 1992 con la vigencia de una sola regulación para todo el ámbito de la Comunidad Europea quedando consiguientemente desplazados los vestigios de legislaciones nacionales diferenciadas.

Es claro que con la implantación del "mercado único" los requisitos sanitarios de los diversos productos se impondrán a los mismos con independencia de su destino en el tráfico, esto es, tanto si se comercializan sólo en el seno del Estado de origen como si se comercializan en otro Estado miembro.

\subsection{Sus consecuencias}

Es opinión doctrinal unánime que la incorporación de España a la Comunidad Europea no produce ningún efecto interno de redistribución de competencias entre las Administraciones Públicas. Cada una de ellas continua ostentando las que le corresponden según el bloque de la constitucionalidad.

Sin embargo, la implantación del "mercado único" supondrá una modificación de las pautas tradicionales de la actuación administrativa en materia sanitaria y ello debe determinar, si no un cambio en la titularidad de la competencia, sí un giro en la forma de ejercicio de la misma.

La necesidad de una modificación en la forma de ejercicio de la competencia por la Administración titular de la misma viene determinada en el caso de España por un doble condicionante: porque la nueva legislación europea modifica los instrumentos tradicionales de 
acción administrativa, de un lado, y porque, de otro, podrian producirse "vaciamientos competenciales" del Estado respecto de las Comunidades Autónomas y viceversa.

\subsubsection{LA MODIFICACION DE LOS TRADICIONALES INSTRUMENTOS DE LA ACCION AD- MINISTRATIVA}

Como se ha indicado, si en materia de sanidad interior al Estado le corresponde dictar la normativa básica, en materia de sanidad exterior ostenta competencia exclusiva, es decir, la plenitud de las funciones normativas y ejecutiva.

En materia de "sanidad exterior, el Real Decreto 1418/1986, de 13 de junio, enmarca las funciones que corresponden al Ministerio de sanidad y Consumo en esta materia. Tras definir en el artículo $1 \%$ la sanidad exterior como la que se refiere a la "vigilancia y control de los posibles riesgos para la salud derivados de la importación, exportación o tránsito de mercancías y del tráfico internacional de viajeros", su artículo $2^{\circ}$ precisa las funciones que ello conlleva, siendo las más relevantes a los efectos de este trabajo:

“a) Las relaciones con los Organismos sanitarios y de consumo internacionales......

c) Control y vigilancia higiénico-sanitaria de puertos y aeropuertos de tráfico internacional, así como de los puestos y de las terminales aduaneras TIR y TIF.

d) Control y vigilancia higiénico-sanitaria en el tráfico internacional de:

* Personas.

* Cadáveres y restos humanos.

* Animales y sus productos, ....

* Mercancías, ...."

De lo anterior, así como del resto del articulo del Real Decreto $1418 / 1986$, se deriva que las funciones ejecutivas en esta materia se realizan en gran medida en puertos $y$ fronteras 0 sobre el tráfico internacional de mercancías y personas.

Ello ha sido constatado por el Libro Blanco de la Comisión para el Consejo Europeo ("La consecución del Mercado Interior", Junio de 1985) que en el apartado relativo a la "Salud" (epigrafes 39 a 43) pone de relieve:

* "En lo que se refiere a la política sanitaria, las fronteras se utilizan para la realización de controles veterinarios y fitosanitarios. Estos controles se deben a las diferencias existentes entre las situaciones y las normas sanitarias de los distintos paises, las cuales justifican la intervención de las autori- 
dades nacionales para comprobar que los productos importados cumplen su propia legislación."

* “La Comunidad se ha propuesto aplicar un programa para la armonización .... Con todo, incluso en los casos en que se ha llevado a cabo la armonización, siguen sin suprimirse los controles en las fronteras, .... Se han adoptado determinadas medidas para trasladar al interior del pais el control de los certificados veterinarios y fitosanitarios, pero para que esta práctica se generalice es preciso que los Estados miembros acepten considerar que las mercancías destinadas a la exportación han sido debidamente controladas en el pais exportador." (epigrafe 39)

* "En una etapa posterior, para alcanzar el objetivo de la eliminación de los controles fronterizos internos de aquí hasta 1992, habrá que conseguir que los controles veterinarios (animales vivos y productos animales) y fitosanitarios se limiten al lugar de salida. Por el contrario, los controles de los certificados veterinarios y fitosanitarios habrán de efectuarse en el lugar de destino (al igual que el control de los productos cuando haya razones para suponer la existencia de prácticas fraudulentas o de negligencias)." (epígrafe 40)

* "Con objeto de facilitar tal proceso, procede adoptar normas comunes adicionales para los intercambios entre los Estados miembros y para las importaciones procedentes de terceros paises en cuando a los animales y productos animales que carecen aún de dichas normas. Los productos animales que se ajusten a ellas recibirán una marca comunitaria. Además, los servicios de vigilancia del pais de origen deberán someter a las mercancías destinadas a ser consumidas en otros paises de la Comunidad a un intenso control con arreglo a los procedimientos armonizados. La mutua confianza se reforzaría mediante el nombramiento de inspectores comunitarios encargados de verificar la buena ejecución de los controles. Además, procedería establecer en el marco de la Comunidad una cooperación entre los Estados miembros en su lucha contra las prácticas fraudulentas, y definir normas sobre responsabilidad en caso de daños resultantes de prácticas fraudulentas o de negligencias." (epigrafe 41).

\subsubsection{La "yuxtaposicion" de las materias y el posible "VAciamiento" COMPETENCIAL}

De lo anterior se derivan dos consecuencias trascendentes. De un lado, los controles se irán físicamente desplazando desde las 
"fronteras" al "interior del país". De otro, puesto que el mercado será "único", las medidas y controles a aplicar lo serán con carácter general con lo cual han de imponerse tanto respecto de los productos que se comercialicen en el interior del Estado como respecto de los que se comercialicen en otros Estados miembros.

Esta doble consecuencia da lugar a una verdadera "difuminación" de los contornos de las materias "sanidad interior" $y$ "sanidad exterior" de modo que,aunque no se produzca una alteración del sistema de distribución de competencias, resulta de considerable dificultad determinar qué medidas o controles son propios de cada una de las materias citadas puesto que la normativa europea ha producido una verdadera "yuxtaposición" de las mismas.

La búsqueda de soluciones adecuadas resulta tanto más necesaria cuanto que, con planteamientos extremos, podría sostenerse por cada parte que la materia aplicable es, por imperativo del devenir del "mercado único", mera "sanidad interior" o bien "sanidad exterior" necesariamente. Es claro que el mantenimiento por una Administración de una de estas tesis conlleva el "vaciamiento" de la competencia de la otra Administración.

Resulta, pues, urgente y necesario encontrar criterios armonizadores del ejercicio competencial de cada Administración, siendo previsible que, de no lograrlo, se produzca una nueva fuente de conflictividad entre el Estado y las Comunidades Autónomas de considerable entidad cuantitativa.

\subsection{Tesis que se propugna}

\subsubsection{LA NECESIDAD DE COLABORACION ENTRE ADMINISTRACIONES}

La incorporación a la Comunidad Europea debe conllevar un cambio importante en los modos tradicionales de la actuación administrativa ya que las Instituciones Comunitarias ostentan atribuciones normativas y ejecutivas que condicionan los comportamientos de las Administraciones nacionales.

El propio Libro Blanco citado pone de manifiesto la necesidad de que los Estados modifiquen sus comportamientos tradicionales cuando en esta materia indica:

a) Que debe regir el principio de la "mutua confianza". (epigrafes 39 y 41 )

b) Que "la mutua confianza se reforzaría mediante el nombramiento de inspectores comunitarios encargados de verificar la buena ejecución de los controles" (epígrafe 41).

c) Que, "además, procedería establecer en el marco de la Comunidad una cooperación entre los Estados miembros 
.... y definir normas sobre responsabilidades en caso de prácticas fraudulentas o de responsabilidades" (epígrafe 41).

En definitiva, el camino hacia el mercado único supone un nuevo modelo de funcionamiento administrativo donde las diversas autoridades competentes estrechan sus conexiones y garantizan mediante nuevas fórmulas la eficacia de los nuevos criterios. El nuevo sistema debe garantizar en lo relativo a España al menos el mismo nivel de coordinación y eficacia actualmente existente, para lo cual es necesaria la participación de todas las Administraciones implicadas.

Parece que si la normativa comunitaria establece criterios basados en la "colaboración" y "mutua confianza" entre los Estados miembros y la misma no determina qué Administración es competente en el seno de cada Estado (principio de "autonomía institucional"), tales criterios deben necesariamente presidir las actuaciones en España. Estas técnicas de colaboración son las que, sin desconocer el "principio de la competencia", permitirán superar la "yuxtaposición" de las materias a las que se ha aludido, atribuyendo a cada Administración las funciones correspondientes.

Por lo demás, ésta actuación en colaboración en materia de "sanidad exterior" es ya un imperativo del derecho positivo. La Ley 14/1986, de 25 de abril, General de Sanidad prevé en su Disposición Final octava que "el Gobierno, mediante Real Decreto, adoptará las medidas necesarias para la actuación conjunta de varias Administraciones Públicas a efectos de sanidad exterior y para que pueda reconocerse validez y eficacia a los mismos efectos a determinadas inspecciones en origen $u$ otros controles concretos que se juzguen suficientes, realizados por los servicios técnicos de las Comunidades Autónomas u otras Administraciones Públicas."

Esta previsión legal ha sido recogida por el Real Decreto 1418/1986 referenciado que, al referirse en su artículo $2^{\circ} .2$. al ejercicio de las funciones estatales en materia de "sanidad exterior", establece que "se realizará conforme a lo establecido en el artículo 38.3 y disposición final octava de la Ley General de Sanidad", precisando que se observarán distintas formas de cooperación y coordinación (convenios, conciertos, etc.) "hasta tanto se regulan" las citadas previsiones legales.

En definitiva, parece que para que las competencias del Estado en materia de "sanidad exterior" no supongan, en el proceso de consecución del "mercado único" y con la implantación de este, un vaciamiento competencial de las competencias autonómicas en materia de "sanidad interior" habría que tener en cuenta:

a) Que la "yuxtaposición" de ambas materias requiere del establecimiento de instrumentos de coordinación nuevos y eficaces que aseguren tanto las funciones ejecutivas de las Co- 
munidades Autónomas como las responsabilidades del Estado.

b) Que es asimismo imprescindible para evitar duplicidades que se reconozca "validez y eficacia a los mismos efectos a determinadas inspecciones realizadas por los servicios técnicos de las Comunidades Autónomas u otras Administraciones Públicas."

\subsubsection{Concurrencia de la Materia "SANitaria" Y del "COMERCIO exterior":} LA DETERMINACION DE LA PREVALENCIA

Lo hasta aquí indicado carecería de virtualidad práctica si se considerara que las regulaciones y actuaciones en el ámbito de la "sanidad exterior" son ante todo regulaciones propias de la materia "comercio exterior". Aunque el "comercio exterior"tenga en cada caso la operatividad que imponga el supuesto concreto, sí que parece conveniente tener en cuenta que, puesto que con la implantación del "mercado único" las mercancías circularán sin trabas por dicho espacio, la prevalencia de esta materia debe ponderarse suficientemente, pues en caso contrario las habilitaciones relacionadas con ella desplazarían a los otros títulos en presencia. En definitiva no parece que toda regulación sobre las mercancías, por el hecho de que las mismas hayan de circular entre los Estados de la Comunidad Europea, pueda considerarse amparada en el "comercio exterior": la fuerza atrayente de este título podría pervertir el reparto constitucional de competencias desplazando las teleologías concretas de cada regulación o acto.

\section{LA SENTENCIA 252/88, DE 20 DE DICIEMBRE}

Esta Sentencia en relación con tres Reales Decretos y una resolución relativos a las condiciones que deben reunir los mataderos, salas de despiece y almacenes frigorificos autorizados para el comercio intercomunitario (con esta expresión, igual que con la de comercio intracomunitario se hace referencia al comercio entre Estados miembros de la Comunidad Europea), ofrece importantes elementos de reflexión en relación con los aspectos que aquí nos ocupan.

Los aspectos controvertidos eran los siguientes:

- En primer lugar, se trataba de determinar si es el Estado o la Comunidad Autónoma la Administración competente para autorizar los mataderos, salas de despiece, etc, que pretendan participar en el comercio entre Estados de la 
Comunidad Europea, asi como para retirar la autorización cuando no cumplan las condiciones exigidas.

- En segundo lugar, se trataba de concretar qué Administración nombraba al "veterinario oficial" encargado de controlar las citadas instalaciones a efectos de garantizar el cumplimiento de los requisitos exigidos.

La Sentencia ofrece un considerable interés ya que es la primera que ha recaído sobre aspectos directamente conectados con la normativa comunitaria y su aplicación a España. A continuación, se analizará la misma, adelantándose ya que se trata de un pronunciamiento complejo y rico que en ocasiones no ha sido adecuadamente "leído", en cuanto que se le atribuya una dimensión centralizadora que, como se tratará de argumentar, está lejos de poseer.

Los aspectos que deben resaltarse son los siguientes:

a) En primer lugar, el Tribunal confirma que la normativa comunitaria no prejuzga las autoridades que en el orden interno son las competentes para adoptar las medidas de que se trate. En este sentido, la Sentencia puntualiza:

- Que son "las reglas internas de delimitación competencial las que en todo caso han de fundamentar la respuesta a los conflictos de competencia" (Fundamento Jurídico 2).

- Aunque las Directivas hagan referencia en este caso a la "autoridad central competente del Estado miembro", ello no supone atribución de competencias al Estado:

"Lo que ahora cabe decir es que estas reglas se limitan a precisar que son las Autoridades Centrales de cada uno de los Estados miembros de la CEE...... las responsables de que las autorizaciones se concedan y mantengan .... sin prejuzgar por consiguiente cuál deba ser la Administración competente -si la estatal o la autonómica- para la concesión de dichas autorizaciones y para velar por el mantenimiento de las condiciones previstas" (Fundamento Jurídico 2).

b) Como es habitual, la Sentencia determina los títulos habilitantes que resultan aplicables a partir de la apreciación de los objetivos y finalidad de las normas impugnadas.

En este sentido, analizadas las habilitaciones materiales argumentadas por las partes, el Tribunal concluye que las materias directamente afectadas son las de la "sanidad exterior" y el "comercio exterior":

"No puede dejar de advertirse que las mismas afectan directamente a las condiciones sanitarias exigidas por las Directivas 
comunitarias para el comercio en el ámbito de la CEE y que, por consiguiente, los títulos competenciales aquí relevantes de modo directo son los relativos a la sanidad y al comercio. Tampoco cabe desconocer, junto a ello, que las prescripciones y actuaciones sanitarias cuyo cumplimiento asi condiciona el comercio intracomunitario pertenecen, por su fin $y$ por su objeto, al ámbito que se propio, respectivamente, del comercio y de la sanidad exteriores, pues mediante los $\mathrm{Re}$ ales Decretos en conflicto el Gobierno ha adoptado, en cumplimiento de las Directivas comunitarias, una regulación específica para los intercambios comerciales exteriores, en el marco de la CEE, regulación aún hoy separada de la que ordena el comercio interior $y$ en la que se contienen unas prevenciones que entran, con naturalidad, en el concepto de la "sanidad exterior" (Fundamento Juridico 2)

Esta determinación de las materias afectadas directamente por el conflicto, ha sido criticada doctrinalmente. Así, José María Baño León en su artículo "La ejecución autonómica del Derecho Comunitario ante el Tribunal Constitucional" (Revista Española del Derecho Administrativo, no 62, abril-junio 1989).

Respecto de que sean las materias de la "sanidad exterior" y el "comercio Exterior" las determinantes de la competencia, señala José María Baño:

“Esta justificación se nos antoja, sin embargo, poco convincente si se atiende al alcance de la competencia discutida. Se trata simplemente de competencias de ejecución administrativa, ... Partiendo del carácter meramente "ejecutivo" de la competencia y del hecho de que la Generalidad de Cataluña tiene atribuciones en materia de inspección sanitaria, sobre agricultura y ganadería, el Tribunal podría haber convenido en una conclusión radicalmente opuesta a la fallada ... Contra lo que sostiene la Sentencia del Tribunal Constitucional, que comentamos, las medidas de ejecución del Derecho comunitario no tienen como "ratio" la sanidad o el comercio exteriores. Por el contrario, la "ratio" es la sanidad y el comercio interiores, es decir, los que se desarrollan entre los Estados miembros de la Comunidad...

Entre los paises miembros de la Comunidad a efectos comunitarios no existen las relaciones exteriores, cuando la Comunidad ejerce una de sus competencias. La regulación del comercio entre los Estados miembros es siempre una materia interior comunitaria... Cierta- 
mente que la regulación producto de las directivas está separada de lo que regula nuestro comercio interior; pero también es cierto que esa regulación está separada de la que rige para el comercio de España con países no comunitarios.

Lo propio cabe decir del título "Sanidad exterior"... La cita se justifica por la importancia de los argumentos vertidos, argumentos que constituirán el núcleo de los debates que sin duda se han de seguir en aspectos como los aquí analizados, a los que la implantación del "mercado único" añade mayor complejidad.

Dichos argumentos requieren un comentario detallado por las siguientes razones:

* Parece que el argumento central de José Maria Baño, aceptando que la determinación de la competencia se derive de la "finalidad" de la norma, se sitúa en que se ha transformado la "finalidad" de las Directivas, de modo que lo que según estas sería "comercio y sanidad interiores" a la propia Comunidad, según los Reales Decretos sería "una regulación para el comercio exterior."

Sin embargo, las Directivas no garantizan en este caso todavía la existencia de un verdadero "mercado interior"comunitario sino que propenden a su implantación a través de la armonización de legislaciones nacionales diferentes. Una vez traspuestas estas Directivas por los diferentes Estados miembros, no por ello se logra un único mercado europeo de carnes, sino que coexisten los intercambios entre Estados amparados en las citadas Directivas con mercados nacionales regulados por legislaciones que mantienen criterios diferentes a los de aquellas.

Así, en España en el momento de entrada en vigor de los Reales Decretos 1754 y 1755/86, coexistían mataderos e instalaciones que por cumplir las Directivas podian realizar intercambios con otros Estados miembros, junto con otros mataderos que sólo estaban habilitados para el comercio nacional. Es precisamente esta dualidad de instalaciones, habilitadas unas sólo para el comercio en el seno del Estado y habilitadas las otras para el comercio intracomunitario, lo que, haciendo mérito de la apreciación de José María Baño de que la finalidad de las Directivas es tener a implantar un "comercio interior comunitario" no conduce, sin embargo, a su conclusión, ya que son muy diferentes los contenidos de los Reales Decretos referenciados 
respecto del contenido de la regulación española a efectos internos y ello sólo permite concluir que mientras los primeros se inscriben en el área de la sanidad y comercio exteriores, los segundos lo hacen en el de la sanidad y comercio interiores.

Este criterio de que los intercambios entre Estados miembros es todavía hoy "exportación" es reconocido por el propio Libro Blanco citado cuando, como se ha reseñado más arriba, en el mismo se lee: "es preciso que los Estados miembros acepten considerar que las mercancías destinadas a la exportación han sido debidamente controladas en el país exportador."

Precisamente por ello, hay que resaltar la justicia del criterio de la Sentencia 252/1988, cuando al referirse a "la regulación especifica para los intercambios exteriores" de los Reales Decretos litigiosos la califica de "regulación aún hoy separada de la que ordena el comercio interior".

Con ello, el Tribunal pone de relieve la existencia de dos regulaciones distintas en la esfera sanitaria, regulaciones que obedecen a finalidades asimismo distintas y ello obliga a adscribir cada una de ellas a la "materia" que el bloque de la constitucionalidad prevé al efecto.

* Tampoco resulta aceptable que porque la regulación del comercio de carnes entre España y los restantes Estados de la Comunidad Europea esté "separada de la que rige para el comercio de España con países no comunitarios" (pág. 264 de la revista citada) se pueda concluir que la primera regulación sería inscribible en el "comercio interior" y sólo la segunda en el "comercio exterior".

En ambos casos se trata de regulaciones de "comercio exterior", especialmente en la fecha de la controversia.Las normas de comercialización con otros Estados, miembros o no de la CEE, pueden contener orientaciones diferenciales y, así, España podría comercializar de forma distinta sus productos en un continente o grupo de países respecto de otros. Y en ambos casos se trataría de "comercio exterior".

* Precisamente por ello resulta tan ajustada la apreciación comentada de la Sentencia. Y conviene profundizar aún más en ella. Nótese que se habla de regulaciones "aún hoy separadas". Con ello se pone de relieve por el Tribunal que en un futuro pueden no estarlo y que no lo estarán con toda seguridad cuando el "mercado único" sea realidad. 
Será en el momento de la efectiva implantación del "mercado único", (cuando coincidan las regulaciones de sanidad interior en sentido estricto y las de sanidad en el seno de dicho mercado único), cuando se produzca el fenómeno de "yuxtaposición" aludido más arriba, no ya exclusivamente de las "regulaciones" sino también de las materias "sanidad interior" y "sanidad exterior" (sólo, naturalmente, respecto del mercado europeo).

Por ello, habrá que preguntarse, para ese futuro que ya es inmediato, por el "destino" de ambas materias.

¿Es que una de ellas podría "absorber" a la otra de modo que la Administración competente en la materia "absorbida" quedará "vaciada" de su competencia al respecto?

Santiago Muñoz Machado ha estudiado un problema que puede trasladarse aquí para ver si guarda conexión con el tema suscitado.

En el bloque de la constitucionalidad las materias "sanidad" $y$ "seguridad social" son materias "separadas " y es conocido que por prescripción de nuestro ordenamiento determinadas prestaciones sanitarias se inscriben en el ámbito de la "seguridad social" y no en el de la "sanidad". Ello determina que la competencia sobre estas prestaciones puedan ostentarlas las Comunidades Autónomas competentes en materia de "seguridad social" pero no aquellas otras que sólo lo son en materia sanitaria.

Santiago Muñoz Machado se plantea este asunto en su "Derecho Público de las Comunidades Autónomas" (página 571 y siguientes) para analizar las consecuencias de una hipotética reforma del sistema sanitario en el sentido de que dicha reforma integrará dentro del Sistema Sanitario las funciones y prestaciones que estaban inscritas en el ámbito de la "seguridad social". Y concluye que en nuestro ordenamiento, si se produjera esa integración unitaria de las funciones y prestaciones sanitarias (no es ahora la ocasión de analizar el tratamiento dado a este asunto por la Ley General de Sanidad), "el contenido del concepto "sanidad" manejado en el artículo 148.1.21 conocerá entonces una ampliación" (página 572).

Es decir, para Santiago Muñoz Machado es posible que las "materias" constitucionales puedan verse reinterpretadas en sus contenidos como consecuencia de modificaciones normativas. Con ello se separa 
de la doctrina de la "petrificación", construida por la jurisprudencia austriaca, que considera que hay que interpretar los preceptos constitucionales según el alcance que tuvieran en el momento de su elaboración.

No parece que el Tribunal Constitucional haya empleado nunca argumentos similares a los de la doctrina de la "petrificación" sino que su argumentación enlaza habitualmente con el análisis del derecho vigente y son varias las sentencias que contienen invocaciones al "ius adveniens".

Aceptando que las "materias" puedan experimentar readaptaciones derivadas de las modificaciones legislativas, no parece, sin embargo, que los cambios que suponen la implantación del "mercado único" conlleven la desaparición de la "sanidad exterior referida al espacio europeo" en beneficio de la "sanidad interior" ni, mucho menos aún, lo contrario.

Que la "sanidad exterior en el mercado único" sigue teniendo sustantividad como materia puede sostenerse porque:

- Existen algunas materias (el "comercio exterior",la "sanidad exterior" y,con una dimensión especial, las "relaciones internacionales") cuyo "telos"conecta con la propia existencia del Estado. Todas las actividades propias de estas materias se atribuyen al Estado, tanto por los efectos que las mismas surten fuera de España como por las consecuencias que las mismas tienen en el conjunto del territorio español cuando se ejercitan por los otros Estados. Ambos efectos (hacia fuera y hacia dentro) justifican las competencias del Estado.En definitiva, si la integración en la Comunidad Europea no altera la distribución de competencias, tampoco la altera el "mercado único".

Puesto que a ello hay que añadir que la propia normativa comunitaria atribuye al Estado importantes funciones y responsabilidades, parece que la "sanidad exterior en el seno del mercado único" debe tener sustantividad propia, si bien, como se argumentará, buena parte de las funciones tradicionales del Estado deben pasar a ser ejecutadas por las Comunidades Autónomas. La Sentencia 252/88 contiene un párrafo que puede avenirse con esta tesis cuando expresa:

"Tanto la necesidad de proporcionar al Gobierno los instrumentos indispensables para desempeñar la 
función que les atribuye el artículo $93 \mathrm{CEE}$... como, de otra parte, el hecho de que sea la Administración Central del Estado ... la competente para realizar actuaciones que, cuando no está presente esa conexión con el exterior,corresponden a la Administración Autonómica...."

- La identidad de las regulaciones no fundamenta, sin más, esa absorción. Piénsese, a título de ejemplo, que la normativa sanitaria interna de un país tercero fuera idéntica a la de la Comunidad Europea y, por tanto, a la española: los intercambios de animales vivos o de carnes entre España y dicho país tercero no por eso serian encuadrables en la materia "sanidad interior". En definitiva, es el especial "telos" de esta materia la que determina la pervivencia de funciones que le son sustantivas.

Se decia antes que si la "sanidad exterior" no se disolvía en "sanidad interior" en el mercado único,mucho menos puede sostenerse lo contrario. Las funciones tradicionales de la "Sanidad exterior" son puntuales y se conectan con actuaciones que se desarrollan fundamentalmente en fronteras, puertos y aeropuertos (autorizaciones de importación y exportación, prohibiciones de entrada o salida, determinación de cuarentenas en aquellos emplazamientos, etc.). No puede sostenerse que, por imperativo de las Directivas Comunitarias, el Estado "expanda" sus funciones tradicionales de la sanidad Exterior y realice "autorizaciones" en origen de centros, instalaciones, etc., ni que realice los "controles" habituales sobre las mismas.

En este sentido, como ya se ha dicho, la nueva normativa comunitaria sí que conlleva importantes readaptaciones en las Administraciones: los controles ya no se harán en frontera sino en origen, se implantará el principio de la "mutua confianza", etc. Todo ello determina que las habituales actuaciones ejecutivas de "sanidad interior" las hayan de realizar las Comunidades Autónomas, aunque tengan trascendencia "exterior". Naturalmente, ello obligará a perfeccionar los mecanismos de articulación entre el Estado y las Comunidades Autónomas pues aquel también asume funciones específicas en el nuevo ordenamiento.

En conclusión, las materias "sanidad exterior" e "interior" deben seguir teniendo su propia especificidad en el seno del "mercado único', si bien sometidas a necesarias 
readaptaciones que impondrán que las actuaciones de cada Administración se sustenten en la colaboración mutua.

* Existe otra preocupación en el artículo de José María Baño que es perfectamente compartida. Se trata de la tentación intelectual de convertir cualquier regulación que afecte al "mercado único" en materia de"comercio exterior", expresándose en términos constitucionales.

Ello produciría una perversión radical del orden de competencias pues, por decirlo con sus palabras, "será muy difícil encontrar normas comunitarias que no tengan incidencia en el comercio exterior en el sentido que lo entiende el Tribunal Constitucional, es decir, comercio intercomunitario. Si el comercio intercomunitario se termina por subsumir en el comercio exterior sin atender a la materia sustantiva que queda afectada por la norma comunitaria, es difícil pensar cual puede ser la directiva o reglamento que la Administración Autonómica pueda aplicar administrativamente por sí misma."

* En conclusión, no puede sino suscribirse la interpretación que la Sentencia realiza respecto de la apreciación de las "materias" que determinan correlativamente la Administración competente.

c) Teniendo en cuenta que las materias afectadas son la sanidad exterior y el comercio exterior, el Tribunal concluye que ni la Resolución citada ni.... los Reales Decretos 1754 y $1755 / 1986$.... han lesionado, pues, las competencias de la Comunidad Autónoma" (Fundamento Jurídico 3).

De aquí que el fallo determine que corresponde al Estado la titularidad de la competencia para otorgar las autorizaciones a los mataderos e instalaciones que puedan intervenir en el comercio intercomunitario, de un lado, $y$, de otro, también la competencia para efectuar el nombramiento del "veterinario oficial".

d) Resultaría simplificador dar por concluido aquí el análisis de la Sentencia 252/88, entendiendo que la misma habría avalado cualquier actuación ejecutiva que pudiera realizar el Estado en los supuestos análogos contenidos en las numerosas Directivas que se están trasponiendo a nuestro ordenamiento.

Una vez apreciada la materia aplicable, la conclusión del Tribunal resulta irreprochable en los términos en que, como él mismo dice expresamente, se le ha planteado el conflicto. Sin embargo, el Tribunal anticipa que una cosa es la "titula- 
ridad de la competencia" y otra bien distinta es "el modo real de ejercicio" de la misma. En este sentido, los dos últimos párrafos del fundamento jurídico 3 constituyen la clave para una recta interpretación del pronunciamiento en su conjunto. Así, resulta destacable:

* Que el Tribunal resalte que siendo las materias tan citadas de competencia estatal, "no se ha debatido por las partes en los presentes conflictos el modo real de ejercicio de esta competencia y ello nos impide, en consecuencia, someterlo a examen. Es obvio, sin embargo, que el principio general de colaboración antes aludido.... ha de inspirar este ejercicio".

Es decir, el Tribunal considera que si bien la competencia es estatal, no puede ejercerla en solitario sino que la Comunidad Autónoma debe participar de alguna forma en dicho ejercicio.

* Esta "necesidad" de que se ejercite la competencia en colaboración la deriva el Tribunal de que la Comunidad Autónoma es "competente con carácter general ... para la ejecución de los controles e inspecciones que interesan a la actividad comercial interna de productos destinados al consumo humano". Con ello se aprecia que el Tribunal ha tenido en cuenta la asimilación que en el actual contexto se produce entre "sanidad interior" y "sanidad en el mercado único".

* Los aspectos reseñados, contenidos en el fundamento jurídico 3, deben completarse con otra aportación igualmente relevante contenida en el fundamento jurídico 2 , in fine.

EI Tribunal resalta que la colaboración "puede exigir en muchos casos, en relación sobre todo con nuestra incorporación a la CEE, formas de articulación (por ejemplo, realización por la Administración Autonómica de tareas de competencia estatal, con sumisión, en consecuencia, y sólo en cuanto a ellas, a instrucciones y supervisión de la Administración central)".

En la misma dirección de imponer la colaboración se sitúa el mandato de la Sentencia de que los Reales Decretos 1754 y $1755 / 86$ se adapten a lo previsto en el Real Decreto $1728 / 87$, de modo que el "veterinario oficial" sea designado por el Estado "a propuesta de la Comunidad Autónoma" (Fundamento Jurídico 4).

Es decir, el Tribunal no sólo exige el ejercicio en colaboración entre el Estado y las Comunidades Autónomas de la 
competencia, sino que ofrece modalidades técnicas al respecto o consagra las previstas legalmente (asi, la referencia a las previsiones de la Ley General de Sanidad).

En todo caso, parece claro que el Tribunal señala que las Comunidades Autónomas deben realizar normalmente las funciones ejecutivas aunque el Estado se reserve algunas funciones de supervisión o dirección. Ello enlaza también con la preocupación del Tribunal de que el ejercicio ordinario de la competencia no conlleve "cargas innecesarias sobre los administrados"(fundamento jurídico 2), criterio de reflexión lógica que se vería enervado si todas las Administraciones materialmente afectadas ejercieran los controles e inspecciones unilateralmente.

En conclusión, estas orientaciones de la Sentencia son absolutamente concordantes con los planteamientos de José Maria Baño cuando éste, apelando a la "racionalidad", manifiesta la conveniencia de que la ejecución del Derecho Comunitario lo realicen las Comunidades Autónomas.

\section{CONCLUSIONES Y PROPUESTAS}

Serían las siguientes:

\subsection{Conclusiones}

a) Con la puesta en marcha del proceso que conduce al "mercado único" en el seno de la Comunidad Europea, se ha producido una armonización de las legislaciones de sus Estados miembros en materia de intercambio de productos que presentan incidencia sanitaria.

b) No obstante esta armonización, aún subsisten dos tipos de mercados en el seno de la Comunidad.

* El mercado ya armonizado, que permite que circulen por él los productos que cumplen determinados criterios.

En esta supuesto, la regulación aplicable aún se inscribe en las materias "sanidad exterior" $y$ "comercio exterior".

* Los mercados nacionales no armonizados, en cuyo seno circulan los productos que no pueden hacerlo en el anterior.

En este supuesto, respecto del mercado español, las materias aplicables son las de "sanidad interior" $y$ "comercio interior". 
c) El camino hacia el "mercado único" impone la paulatina supresión de los "mercados nacionales".

d) La constitución efectiva del "mercado único" conlleva en el Estado español la identidad de la normativa de sanidad y comercio "interiores" respecto de la sanidad y comercio en el seno del "mercado único".

Ello determinará la "yuxtaposición" de las materias "sanidad y comercio interiores", de un lado, y "sanidad $y$ comercio exteriores", de otro.

e) Esta "yuxtaposición" es compatible con la identidad propia de cada materia, si bien con importantes readaptaciones en sus contenidos sustantivos.

f) De ello debería seguirse una nueva modalidad de ejercicio de las competencias, caracterizada por la intensificación de la coordinación y, especialmente, de la colaboración entre Administraciones.

g) Si la colaboración es ya una exigencia en las relaciones entre los Estados de la Comunidad Europea, las relaciones administrativas internas deberian regirse, entre otros, por los siguientes principios:

* El de "racionalidad y eficacia" en la gestión, imponiendo los menores costes al ciudadano.

* El de "mutua confianza", que implica la convalidación en principio de los actos de la autoridad correspondiente.

* El de "supervisión" por la Administración responsable de la adopción de las medidas.

* El de "responsabilidad" de la Administración que ha gestionado las medidas.

i) Desde el punto de vista del ordenamiento español, supondría:

* Que sean las Comunidades Autónomas quienes apliquen y ejecuten el Derecho Comunitario aún en aspectos que pudieran ser de competencia estatal (principio de "racionalidad y eficacia").

* Que el Estado convalide las actuaciones de las Comunidades Autónomas (principio de "mutua confianza").

* Que en las actuaciones de competencia del Estado ejecutadas por las Comunidades Autónomas, aquel dirija y excepcionalmente supervise las citadas actuaciones, adoptando en su caso las rectificaciones necesarias (principio de "supervisión").

* Que el Estado y las Comunidades Autónomas respondan de las actuaciones respectivas, imputándoseles las con- 
secuencias derivadas de las irregularidades que se aprecien (principio de "responsabilidad")

\subsection{Propuestas}

Del análisis de las Directivas relativas a intercambio de animales, carnes $u$ otros productos con incidencia sanitaria se derivan diversas actuaciones a realizar por los Estados y cuya concreta atribución puede no resultar pacífica en el caso español.

Los principales aspectos a destacar son:

a) La designación del "veterinario oficial": Este es el encargo de realizar los controles ordinarios de los diversos centros (mataderos, salas de despiece, centros de esperma, mercados de exportación, etc.).

La Sentencia 252/88 ha determinado que la designación debe hacerse por el Estado a propuesta de la Comunidad Autónoma.

Esta solución es sin duda adecuada para el momento presente en que aún no está implantado el mercado único y las materias sanidad "interior y "exterior" están aún "separadas". Sin embargo, cuando el "mercado único" esté constituido lo mas adecuado sería:

* Que la Comunidad Autónoma realice directamente el nombramiento.

* Que el Estado "comunique" (como es preceptivo) dicho nombramiento a la Comunidad Europea, no haciéndolo cuando aprecie elementos fundados que lo desaconsejen (en este supuesto, la colaboración entre ambas Administraciones permitiría salvar la discrepancia de modo rápido).

b) La autorización de los diversos centros: Son aquellos que, en sus diversas modalidades (reprodúzcase aqui la relación del apartado anterior) pueden participar en el comercio intracomunitario.

La Sentencia $252 / 88$ ha atribuído esta competencia al Estado pero no se ha pronunciado sobre su "forma de ejercicio" porque las partes no lo plantearon en el conflicto. De aqui que se proponga:

* Que en la situación actual se siga el modelo del nombramiento del "veterinario oficial", es decir, la autorización la realizaría el Estado "a propuesta de la Comunidad Autónoma". 
* Que una vez constituido el mercado único, sean las Comunidades Autónomas quienes autoricen (o retiren la autorización) y el Estado quien "comunique" a la Comunidad Europea dichas autorizaciones, no haciéndolo en caso de desacuerdo fundado, al igual que se ha indicado en el supuesto anterior.

Nótese que este planteamiento se funda en el criterio de que "lo que hace una Administración no lo debe hacer la otra", esencia de la llamada "competencia en colaboración" tal y como ha sido expuesto por el Tribunal Constitucional en sus Sentencias 11/1986 y 186/1988.

c) La realización de controles: Se trata de los controles que garanticen que los centros o instalaciones autorizados cumplen los requisitos que determinaron la autorización. Los mismos deben corresponder al "veterinario oficial" o a los Servicios veterinarios de la Comunidad Autónoma en los supuestos en que las Directivas prevén esta dualidad.

d) La adopción de medidas sanitarias de prevención o de lucha contra la enfermedad: la determinación de la Administración competente dependerá de ordinario de la índole y localización de la medida:

* Si son medidas a adoptar en frontera, deben corresponder a la Administración del Estado.

* Si son medidas en "origen", esto es, en las granjas mercados, etc., sería la Comunidad Autónoma correspondiente.

e) Comunicación y relaciones con la Comunidad Europea: Se realizarían por la Administración del Estado, sin perjuicio de la participación autonómica en la voluntad estatal según los supuestos.

f) Las nuevas funciones del Estado: En todo caso, el Estado puede conservar una capacidad de "dirección general", instrumentada mediante mecanismos de coordinación, según se expresa en el fundamento jurídico 2 de la Sentencia 252/88.

Es conveniente destacar que la instrumentación por el Estado de las nuevas funciones que exigen sus responsabilidades no es tarea fácil. En todo caso:

* Dichas funciones no deben "reproducir" modelos de actuación ejecutiva propias de la sanidad interior tradicional (autorizaciones, controles, etc.).

* Deben orientarse a crear mecanismos de coordinación y colaboración con las Comunidades Autónomas que le permitan "dirigir" a éstas en lo relativo a las más directas 
responsabilidades estatales garantizado la eficaz relación entre todos los entes implicados.

* Estos criterios ya han sido previstos en la propia Ley General de Sanidad (Disposición Final octava) cuando prevé la necesidad de que se reconozcan, a efectos de la "sanidad exterior", las actuaciones ejecutivas de las Comunidades Autónomas. Parece que el camino debería ser el desarrollo de esa previsión legal, desarrollo al cual se alude en el artículo $2^{\circ} .2$ del antes citado Real Decreto 1418/1986, de 13 de junio.

Madrid, 16 de julio de 1990 